\title{
On the Recent Trend of the Iron and Steel Analysis in Japan*
}

\author{
Report of the Iron and Steel Analysis Division, Joint Research Society
}

\section{By Takuho Ikegami**}

\section{Introduction}

The great progress of analytical chemistry in recent years can be attributed to the improved precision and accuracy in methods of separation, identification and determination produced by various new organic reagents and the introduction of a number of instrumental methods of analysis.

The results of the progress are, of course, taken into the field of iron and steel analysis. They contribute greatly to the quality development and the cost reduction of iron and steel products in our country through their successive utilization on the process and product controls.

This report describes how the iron and steel analysis is in Japan and how the iron and steel manufacturers in Japan are closely co-operating in this field.

\section{Activities of the Iron and Steel Analysis Division}

Every analyst in iron works is inexceptionally anxious to improve the precision and accuracy of his analysis, and is making an effort to overcome difficulties in it. But the rapid progress in science and technique in recent years makes it quite difficult for him to cover the whole field by himself, and a co-operation of analysts is requisite in solving the problems. For this reason the Iron and Steel Analysis Division was established in the Joint Research Society of The Iron and Steel Institute of Japan, and the manufacturers are acting together to solve the most urgent problems in each place by their joint investigations in the Division during which they collect all data from their members.

Thirteen companies are now sending committee members into the Division, and the meetings are held twice a year alternatively in Tokyo and the provinces. After every meeting it is customary for the members to visit analytical laboratories in the nearby iron works.

In the field of chemical analysis, the Division has hitherto dealt with the determination of phosphorous and sulphur in iron and steel and the total analysis of iron ores; and in the field of instrumental analysis, the direct-reading emission spectrometry and fluorescent X-ray spectrometry. Problems of permissible errors in the analysis are also important subjects for discussion.

\section{Determination of Phosphorus in Iron and Steel}

The JIS (Japanese Industrial Standard) methods of determining the amount of phosphorus in iron and steel consist of a ammonium phosphomolybdate vol- umetry and a molybdenum blue absorption photometry. The former method sometimes gives higher values, and the cause was investigated by the co-operation of ten companies with a temporarily established subcommittee.

Extensive analyses on synthetic samples of the standard phosphorus solution mixed with pure iron and examinations on the practical samples with radioactive phosphor as a tracer revealed that the error came from the procedure of washing out the precipitate of ammonium phosphomolybdate. By washing with nitric acid $(2: 10,000)$ in accordance with the JIS method, a little nitric acid sometimes remained to give slightly higher values. On the other hand, the conventional method of washing the precipitate with potassium nitrate $(1 \%)$ solution to the disappearance of acidic reaction gave a slightly lower result because a portion of the precipitate was dissolved into the washings. The modified JIS method which involves thorough washing with nitric acid $(2: 10,000)$ followed by triple washings with potassium nitrate $(1 \%)$ solution gave results agreeable with theoretical values.

The subcommittee was dissolved after the results were sent to the JIS Technical Committee on Analysis together with a recommendation of the amendment of the JIS procedure.

\section{Determination of Sulphur in Iron and Steel}

The JIS method for determining sulphur by barium sulphate gravimetry sometimes gives lower results, and the cause was investigated by the co-operation of nine companies forming a special subcommittee.

Examination on the synthetic samples of the standard sulphuric acid solution mixed with pure iron and on the practical samples with radioactive sulphur as a tracer revealed that agreements with the theoretical values were obtained provided that the barium sulphate was recovered from the concentrated filtrate of washed barium sulphate precipitate. The results were sent to the JIS Technical Committee on Analysis, and the recovery of sulphur from the filtrate was recommended.

Examinations on the combustion volumetry of sulphur led to the conclusion that the heating temperature of sample should be raised to $1,450^{\circ} \mathrm{C}$ from the conventional $1,350^{\circ} \sim 1,400^{\circ} \mathrm{C}$ where reproducibility of the result was lower, and the factor of the standard solution of neutralization titration should be determined by using standard steel, the sulphur content of which was determined gravimetrically.

The methods for determining the trace amount of 
sulphur (c. less than $0.01 \%$ ) were also investigated and the following two procedures were adopted: a gravimetry after the separation of sulphuric acid by the absorption on activated alumina, and an absorption photometry with p-Rosaniline of sulphur dioxide obtained by the combustion of sample in a stream of oxygen. Since the gravimetry involves complicated procedures, it is used only for the determination of standard values of reference steels on which are obtained calibration lines of the absorption photometry for routine works.

\section{Analysis of Iron Ores}

The quality control of iron ores, fundamental materials in the iron and steel industry, is not, of course, beyond the scope of the activity of the Iron and Steel Analysis Division. The Division has a sectional committee on the analysis of iron ores, where analysts from six companies in our country having blast furnaces have re-examined Japanese Industrial Standard fully in detail, and the accuracy and the precision of methods have been improved remarkably. The results were sent to the JIS Technical Committee on Analysis and the JIS methods in this connection were entirely revised.

By chance, in 1961, Japan was named as the executive country for ISO/TC 102 iron ores to provide first drafts of the ISO standard methods for the sampling, chemical analysis, and the physical test of iron ores, and the above methods presented by the committee were given as the draft proposals. The methods proposed are listed in Table 1.

The notable results of joint researches on the analysis of iron ores are as follows.

Table 1. Proposed methods of chemical analysis of iron ores by the Japanese Industrial Standards Committee

\begin{tabular}{|c|c|}
\hline Component & Purport \\
\hline Combined water & $\begin{array}{l}\text { Dehydration at } 750^{\circ} \mathrm{C} \text { in nitrogen stream and } \\
\text { gravimetry }\end{array}$ \\
\hline Total iron & Reduction with $\mathrm{SnCl}_{2}$ and titration with $\mathrm{K}_{2} \mathrm{Cr}_{2} \mathrm{O}_{7}$ \\
\hline Ferrous oxide & $\begin{array}{l}\text { Decomposition in } \mathrm{CO}_{2} \text { stream and titration with } \\
\mathrm{K}_{2} \mathrm{Cr}_{2} \mathrm{O}_{7}\end{array}$ \\
\hline Silicon dioxide & $\begin{array}{l}\text { Dehydration with } \mathrm{HClO}_{4} \text {, treatment with } \mathrm{HF}+ \\
\mathrm{H}_{2} \mathrm{SO}_{4} \text { and gravimetry }\end{array}$ \\
\hline Aluminium oxide & $\begin{array}{l}\text { Separation with MIBK, separation of oxine } \\
\text { complex, treatment with } \mathrm{KBrO}_{3} \text { and } \mathrm{KI} \text {, and } \\
\text { titration with } \mathrm{Na}_{2} \mathrm{~S}_{2} \mathrm{O}_{3}\end{array}$ \\
\hline \multirow{2}{*}{ Phosphorus } & $\begin{array}{ll}\text { 1st method: } & \begin{array}{l}\text { separation of }\left(\mathrm{NH}_{4}\right)_{3} \mathrm{PO}_{4} 12 \mathrm{MoO}_{3} \\
\text { and neutralization titration }\end{array}\end{array}$ \\
\hline & 2nd method: molybdenum blue photometry \\
\hline Sulphur & $\begin{array}{l}\text { Decomposition with } \mathrm{KClO}_{3}+\mathrm{HCl}+\mathrm{HNO}_{3} \text { and } \\
\text { gravimetric determination of } \mathrm{BaSO}_{4}\end{array}$ \\
\hline Manganese & $\begin{array}{l}\text { Oxidation with }\left(\mathrm{NH}_{4}\right)_{2} \mathrm{~S}_{2} \mathrm{O}_{8}+\mathrm{AgNO}_{3} \text { and photo- } \\
\text { metry }\end{array}$ \\
\hline Copper & Photometry with diethyldithiocarbamate \\
\hline Chromium & Photometry with diphenylcarbazide \\
\hline Titanium oxide & Photometry with hydrogen per oxide \\
\hline Calcium oxide & Separation of $\mathrm{CaC}_{2} \mathrm{O}_{4}$ and titration with $\mathrm{KMnO}_{4}$ \\
\hline Magnesium oxide & $\begin{array}{l}\text { Removal of iron with MIBK extraction and } \\
\text { titration with EDTA }\end{array}$ \\
\hline
\end{tabular}

Combined Water: Dehydration by heating in air was altered to that by heating in a nitrogen stream to avoid the interference from organic materials, and an oxide mixture $\left(\mathrm{PbO}+\mathrm{PbO}_{2}\right)$ was placed to remove the influence of sulphur.

Silicon Dioxide: Only a negligible amount of silicon dioxide escaped into the filtrate after the decomposition of a sample with hydrochloric acid and a

Table 2. Laboratories equipped with direct-reading emission spectrometers

\begin{tabular}{|c|c|}
\hline Companies and laboratories & Instruments and the number \\
\hline $\begin{array}{l}\text { Yawata Iron \& Steel Co., Ltd. } \\
\text { Tokyo Res. Inst. } \\
\text { Technical Res. Inst. } \\
\text { Yawata Works } \\
\text { Tobata Works } \\
\text { Hikari Works }\end{array}$ & $\begin{array}{l}\text { JACO } \\
\text { Shimadzu Vac } \\
\text { Shimadzu Vac (X4) } \\
\text { Shimadzu Vac (X2) } \\
\text { Shimadzu Vac }\end{array}$ \\
\hline $\begin{array}{l}\text { Fuji Iron \& Steel Co., Ltd. } \\
\text { Central Res. Inst. } \\
\text { Muroran Works } \\
\text { Kamaishi Works } \\
\text { Hirohata Works }\end{array}$ & $\begin{array}{l}\text { JACO } \\
\text { Baird (X2), ARL Meter, ARL } \\
\text { Vac } \\
\text { Baird, ARL Meter } \\
\text { Baird, ARL Meter }\end{array}$ \\
\hline $\begin{array}{l}\text { Nippon Kokan K. K. } \\
\text { Kawasaki Works } \\
\text { Mizue Works } \\
\text { Tsurumi Works }\end{array}$ & $\begin{array}{l}\text { Shimadzu Vac (X2) } \\
\text { Shimadzu Vac } \\
\text { Shimadzu Vac }\end{array}$ \\
\hline $\begin{array}{l}\text { Kawasaki Steel Corp. } \\
\text { Chiba Plant }\end{array}$ & Baird, Shimadzu Vac (X2) \\
\hline $\begin{array}{l}\text { Sumitomo Metal Industries, Ltd. } \\
\text { Wakayama Works } \\
\text { Steel Works } \\
\text { Steel Pipe Works } \\
\text { Kokura Works }\end{array}$ & $\begin{array}{l}\text { ARL Meter, ARL Vac, Shima- } \\
\text { dzu Vac } \\
\text { Shimadzu Vac } \\
\text { Shimadzu Nor, Shimadzu Vac } \\
\quad \text { (X2) } \\
\text { Shimadzu Vac }\end{array}$ \\
\hline Kobe Steel Works, Ltd. & $\begin{array}{l}\text { ARL Vac (X2), Shimadzu Nor, } \\
\text { Shimadzu Vac }\end{array}$ \\
\hline $\begin{array}{l}\text { Japan Steel Works, Ltd. } \\
\text { Muroran Works }\end{array}$ & Shimadzu Nor \\
\hline Daido Steel Co., Ltd. & ARL Vac \\
\hline Aichi Steel Works, Ltd. & ARL Vac \\
\hline Tokushu Seiko Co., Ltd. & Baird \\
\hline Nippon Yakin Kogyo Co., Ltd. & Shimadzu Nor \\
\hline Nippon Stainless Steel Co., Ltd. & Shimadzu Vac \\
\hline Nissin Seiko K. K. & Shimadzu Vac (X3) \\
\hline Amagasaki Iron \& Steel Mfg. Co., Ltd. & ARL Vac \\
\hline North Japan Special Steel Co., Ltd. & ARL Vac \\
\hline Sanyo Special Steel Co., Ltd. & ARL Vac, Shimadzu Vac \\
\hline Fujikoshi, Ltd. & Shimadzu Vac \\
\hline Mitsubishi Steel Mfg. Co., Ltd. & Baird (X2), Shimadzu Vac \\
\hline Kanto Special Steel Works, Ltd. & Shimadzu Nor \\
\hline Japan Special Steel Co,, Ltd. & Shimadzu Nor \\
\hline Kanto Steel Co., Ltd. & Shimadzu Nor \\
\hline Hitachi Metal Industries, Ltd. & Shimadzu Nor (X2) \\
\hline Tokai Iron \& Steel Co., Ltd. & Shimadzu Vac (X2) \\
\hline \multicolumn{2}{|c|}{$\begin{array}{ll}\text { Notes: } & \\
\text { JACO: } & \text { JACO direct-reading instrumentation. } \\
\text { Baird: } & \text { Baird-Atomic Inc. direct-reading spectrometer. } \\
\text { ARL Meter: } & \text { Applied Research Lab. quantometer. } \\
\text { ARL Vac: } & \text { Applied Research Lab. quantovac. } \\
\text { Shimadzu Nor: } & \text { Shimadzu normal pressure type quantorecorder. } \\
\text { Shimadzu Vac: } & \text { Shimadzu vacuum type quantorecorder. }\end{array}$} \\
\hline
\end{tabular}


fuming treatment with perchloric acid. But an innegligible amount of silicon dioxide remained in the filtrate after the alkali carbonate fusion of insoluble residue and the dissolution of the melt followed by a fuming treatment with perchloric acid, and the recovery of this silicon dioxide improved both the precision and the accuracy of the determination.

Phosphorus: The precision of the volumetric method was improved according to the conclusion of the phosphorus subcommittee. And a highly reproducible absorption photometric molybdenum blue method with hydrazine-sulphate reduction was adopted based on year-long investigations.

Sulphur: The precision of the gravimetric method was improved according to the conclusion of the sulphur subcommittee. Convenient volumetric methods following the heat decomposition which involve neutralization titration, EDTA titration and potassium iodate titration were critically compared, and a potassium iodate method was standardized since it is simple in procedures and free from the influence of fluorine, chlorine etc. However, the method only determines the sulphur dioxide evolvd by the heat decomposition, hence the factor of the standard iodate solution was determined using a reference sample, of which the sulphur content was preliminarily determined by the

Table 3. Elements and their concentration ranges for determination by direct-reading emission spectrometer

(by JIS G1253-1963)

\begin{tabular}{|c|c|c|c|c|}
\hline \multirow{2}{*}{ Element } & \multicolumn{2}{|c|}{$\begin{array}{l}\text { Range }(\%) \text { by normal } \\
\text { pressure type }\end{array}$} & \multicolumn{2}{|c|}{$\begin{array}{c}\text { Range }(\%) \text { by vacuum } \\
\text { type }\end{array}$} \\
\hline & Minimum & Maximum & Minimum & Maximum \\
\hline
\end{tabular}

\begin{tabular}{|c|c|c|c|c|}
\hline $\mathrm{C}$ & - & & 0.01 & 4.5 \\
\hline $\mathrm{Si}$ & 0.005 & 5.0 & 0.005 & 5.0 \\
\hline Mn & 0.01 & 4.0 & 0.01 & 20.0 \\
\hline $\mathrm{P}$ & 0.005 & 0.5 & 0.001 & 0.4 \\
\hline $\mathrm{s}$ & - & & 0.001 & 0.5 \\
\hline $\mathrm{Ni}$ & 0.005 & 30.0 & 0.005 & 30.0 \\
\hline $\mathrm{Cr}$ & 0.005 & 30.0 & 0.005 & 30.0 \\
\hline Mo & 0.001 & 10.0 & 0.001 & 10.0 \\
\hline $\mathrm{Cu}$ & 0.01 & 1.0 & 0.01 & 2.0 \\
\hline W & 0.01 & 15.0 & 0.1 & 25.0 \\
\hline v & 0.01 & 5.0 & 0.001 & 3.0 \\
\hline $\mathrm{Co}$ & 0.03 & 20.0 & 0.002 & 20.0 \\
\hline $\mathrm{Ti}$ & 0.005 & 1.5 & 0.002 & 1.0 \\
\hline $\mathrm{Al}$ & 0.003 & 1.0 & 0.005 & 3.0 \\
\hline As & - & & 0.005 & 0.3 \\
\hline $\mathrm{Sn}$ & 0.004 & 0.1 & 0.005 & 0.3 \\
\hline B & 0.0005 & 0.1 & 0.0005 & 3.0 \\
\hline $\mathrm{Pb}$ & 0.0005 & 0.5 & 0.005 & 0.5 \\
\hline $\mathrm{Zr}$ & 0.005 & 1.0 & - & \\
\hline $\mathrm{Nb}$ & 0.005 & 0.1 & 0.005 & 0.5 \\
\hline $\mathrm{Mg}$ & 0.001 & 0.2 & 0.001 & 0.1 \\
\hline
\end{tabular}

standard gravimetry.

Copper: An influence of platinum was found by the diethyldithiocarbamate photometry, and an alumina crucible was substituted for a platinum crucible for the fusion of insoluble residues.

Vanadium: A newly developed N-benzoylphenylhydroxylamine photometry with an improvement of its reproducibility was adopted as a substitute for the conventional diphenylamine photometry.

Tin: An alternative current polarography with simple procedures was newly introduced, being free from the influence of lead.

Bismuth: The method for bismuth was newly standardized, in which a bismuth-iodide photometry was established.

Lead: The methods for lead were newly standardized, in which a dithizone photometry and a polarography were established.

The Iron Ore Analysis Subdivision carried out extensive and co-operative examinations on the standardized procedures by applying them to common samples for the determinations of combined water, total iron, ferrous oxide, silicon dioxide, manganese, phosphorus, sulphur, copper, titanium oxide, aluminum oxide, calcium oxide, magnesium oxide, nickel, chro-

Table 4. Laboratories equipped with fluorescent X-ray analysers

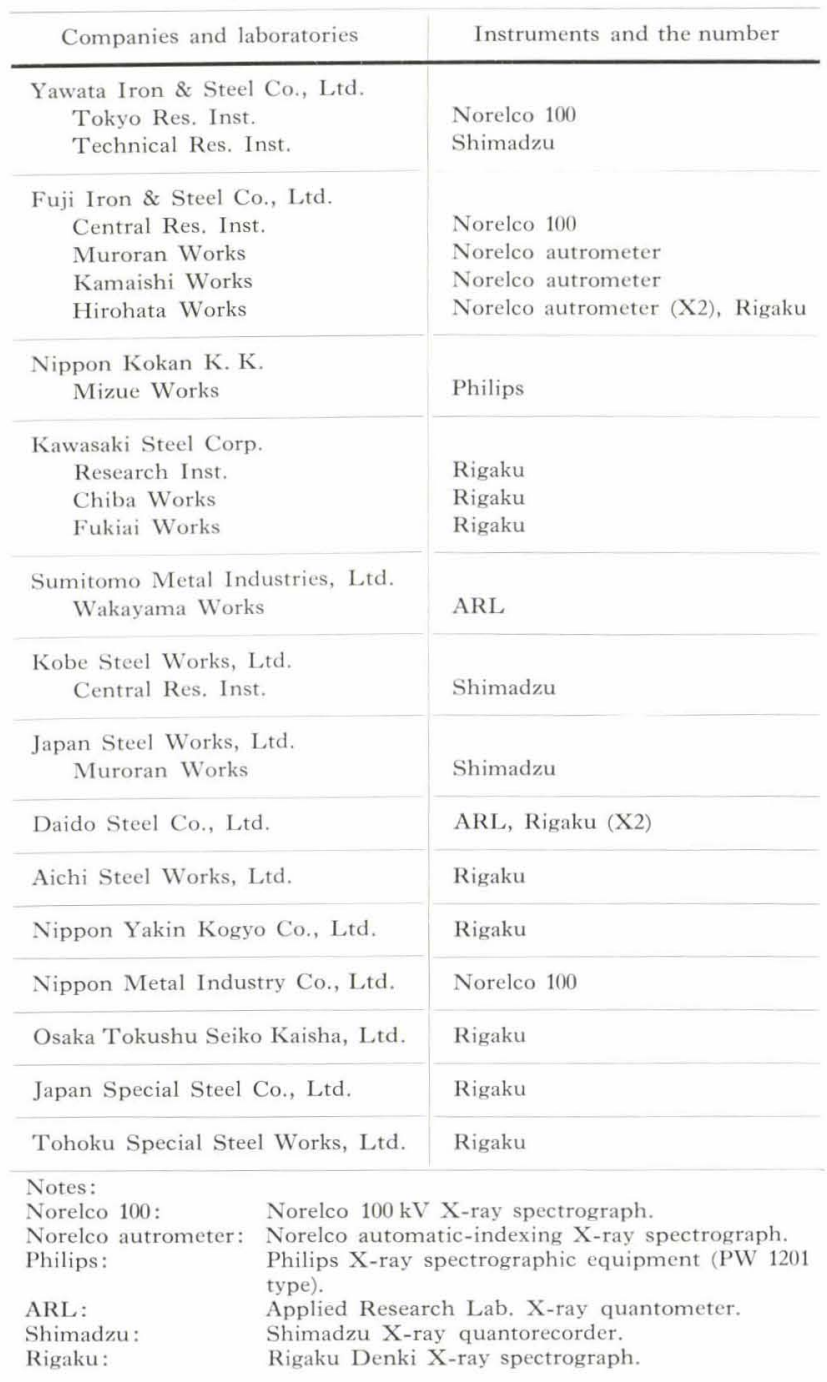


mium, vanadium, arsenic, tin, zinc, lead, and bismuth. The results were statistically examined to determine permissible errors in the analysis for every component.

\section{Errors in the Analysis}

Another subcommittee, the Subcommittee on Analytical Error, is continuing its co-operative investigations on errors in the analysis of iron and steel.

The true error or deviation should be decided upon knowledge of the absolute values of each component, and synthetic samples are usually utilized for these purposes. Practical iron and steel, however, contain miscellaneous elements and synthetic samples closely representing the real compositions of iron and steel are hardly obtainable. In practical examinations, therefore, many skillful analysts in a number of laboratories carried out two independent determinations on a common practical specimen by the same procedure, and from their results were obtained the precision the magnitude of the dispersion of analytical values) of their analyses including segregation factors. The permissible error for a reference sample was defined as the (precision $\times 2$ ), and that for an analytical sample was as the (precision $\times 2 \sqrt{ } 2)$.

The above definition as well as the experimental design of co-operative analyses and the method of calculation for obtaining permissible errors were investigated and decided by the subcommittee, together with the proper use of the values of permissible errors.

The sectional subdivisions and each subcommittee are carrying out extensive joint analyses according to the standardized experimental design, and calculating permissible errors for each method. They have already decided permissible errors for fifteen methods for iron and steel, and thirty six methods for iron ores.

Table 5. Methods for determination of trace elements in iron, steel and iron ores

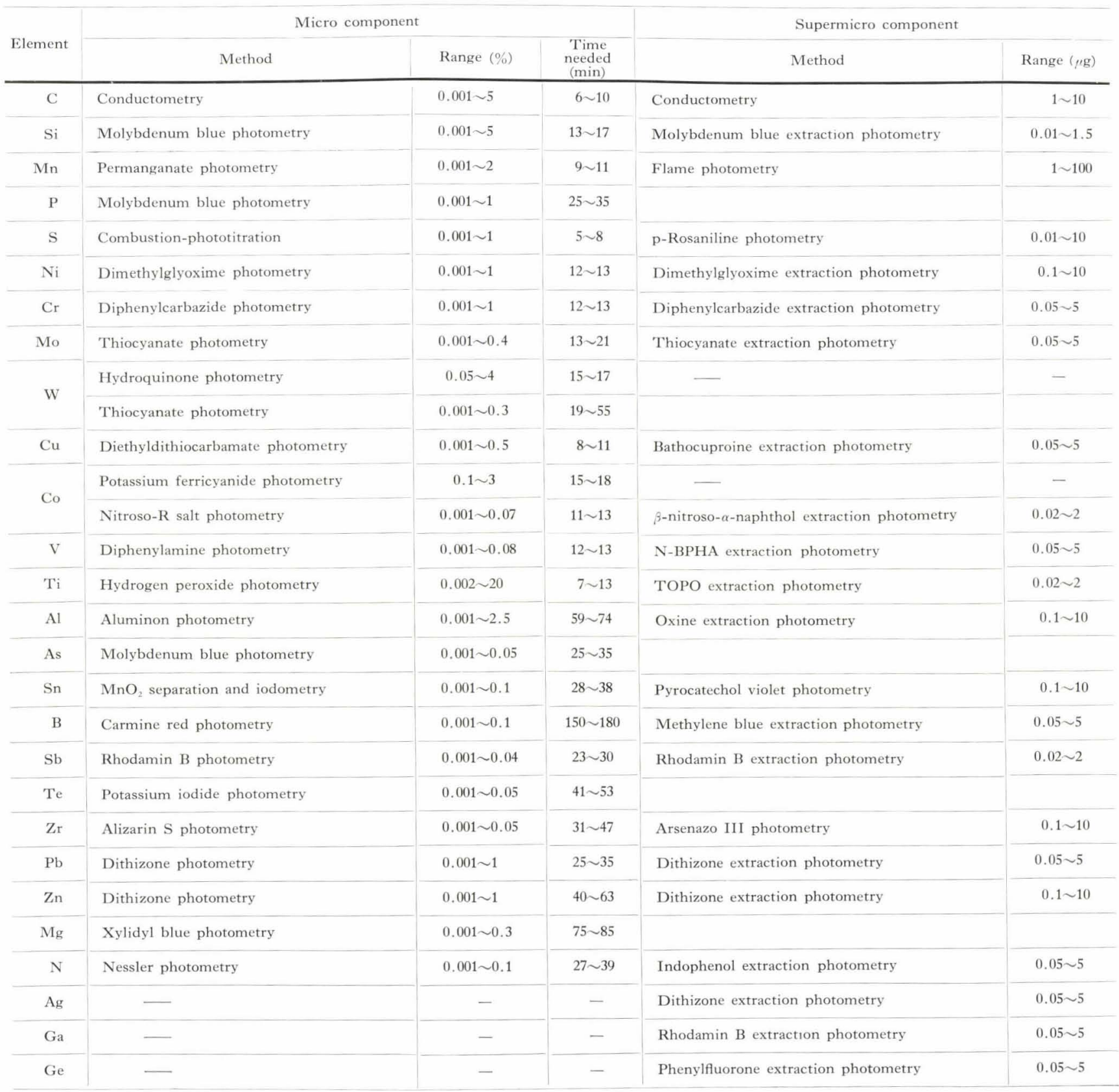




\section{Direct-Reading Emmission Spectrometry}

The direct-reading, normal pressure type or vacuum type emmission spectrometer provides advantages of both rapidity of an analysis and economy by manhand saving. Its increasing numbers are now introduced into the factories to be used for the analysis for quality control or inspection.

The experiences of using these quantometers taught them, however, that there were yet several problems to be solved by co-operative experiments, and the members of thirteen companies have formed the Emission Spectroscopic Analysis Subdivision to develop joint research.

They are performing extensive experiments exchanging their reference samples of wide varieties, to obtain a formula which universally represents analytical errors in quantometers and which is to be used for the comparison of analytical results by different instruments on a common basis. Meanwhile, the sort and the range of concentration of elements in iron and steel, which can be determined with quantometers now available, were tentatively obtained from the results of the joint experiments by all the members. The results were sent to the JIS Technical Committee on Analysis, and the recommended conditions for the determination was adopted in the JIS methods. Possible elements and their amounts are listed in Table 3.

\section{Fluorescent X-Ray Analysis}

Direct-reading fluorescent X-ray analyzers available in recent years have many advantages: the components of relatively higher concentration can be accurately determined by this means as compared with the emission spectrometry and the analysis is done under a non-destructive condition. An increasing number of fluorescent X-ray analyzers has been now introduced into iron and steel works, being applied for the control analysis of iron and steel, slags, ferro-alloys, iron ore, and sinter.

However, on the sort of sample for analysis by this means or the sort and the amount of estimable elements, there are yet indefinite opinions. There remain many problems to be solved, for instance, the method for sample preparation and method of molding of powdery specimen as well as the matrix effects by coexistent elements. For these reasons, the Fluorescent X-Ray Analysis Subdivision has been formed by the members from eleven companies.

The activity of the subdivision is at present directed to iron and steel samples. After the establishment of general procedures for fluorescent X-ray analysis with discussions, the subdivision is now continuing investigations on the conditions for determining the amount of silicon, manganese, phosphorus, sulphur, and copper in ordinary steels, and of silicon, manganese, phosphorus, sulphur, nickel, and chromium in alloy steels.

\section{Others}

The analyses of trace impurities in iron and steel for the complete quality control from raw materials to their products have improved remarkably in Japan in recent years. As seen in some examples of chemical methods listed in Table 5, these improvements are greatly attributable to the development of organic reagents in recent years.

On the other hand, the direct-reading emmission spectrometry plays an important role in the physical methods of trace analysis, and X-ray microanalyzers are equipped in several laboratories (Table 6) to be applied for the analysis of fine structures as to, microscopic segregation, precipitation phase, nonmetallic inclusions, etc.

Table 6. Laboratories equipped with X-ray microanalysers

\begin{tabular}{|c|c|}
\hline Companies and laboratories & Instruments \\
\hline $\begin{array}{l}\text { Yawata Iron \& Steel Co., Ltd. } \\
\text { Tokyo Res. Inst. } \\
\text { Technical Res. Inst. }\end{array}$ & $\begin{array}{l}\text { ARL electron microbe X-ray analyser } \\
\text { Hitachi X-ray microanalyser }\end{array}$ \\
\hline $\begin{array}{l}\text { Fuji Iron \& Steel Co., Ltd. } \\
\text { Central Res. Inst. }\end{array}$ & Hitachi X-ray microanalyser \\
\hline $\begin{array}{c}\text { Nippon Kokan K. K. } \\
\text { Tsurumi Works }\end{array}$ & $\begin{array}{l}\text { Japan Electron Optics Lab. X-ray } \\
\text { microanalyser }\end{array}$ \\
\hline Daido Steel Co., Ltd. & $\begin{array}{l}\text { Japan Electron Optics Lab. X-ray } \\
\text { microanalyser }\end{array}$ \\
\hline Fujikoshi, Ltd. & Hitachi X-ray microanalyser \\
\hline
\end{tabular}

\section{Future Trend}

As stated above, the accuracy and precision in the chemical method of standard analysis of iron and steel will appear to improve still more with the coming development of organic reagents. The introduction of instrumental methods including, in addition to those cited above, solid and gaseous mass spectrometry is now under active investigations. Especially, the instrumental methods are becoming more esteemed as powerful weapons for the automatization of routine metallurgical procedures. 